\title{
Concentração de votos e acordo de acionistas: influências sobre o conservadorismo*
}

\section{Voting rights concentration and shareholders agreement: influences on conservatism}

\begin{abstract}
Alfredo Sarlo Neto
Professor Adjunto do Departamento de Ciênciạs Contábeis do Centro de Ciências Jurídicas e Econômicas da Universidade Federal do Espírito Santo*E-mail: sarloneto@ccje.ufes.br
\end{abstract}

\section{Adriano Rodrigues}

Professor Adjunto do Departamento de Ciências Contábeis da Faculdade de Administração e Ciências Contábeis da Universidade Federal do Rio de Janeiro*E-mail: adriano@facc.ufrj.br

José Elias Feres de Almeida

Professor Adjunto do Departamento de Ciências Contábeis do Centro de Ciências Jurídicas e Econômicas da Universidade Federal do Espírito Santo*E-mail: joseelias@ccje.ufes.br

Recebido em 17.08.2010 *Aceito em 22.10.2010 * $2^{a}$ versão aceita em 08.12.2010

\section{RESUMO}

Este estudo investiga como duas características da estrutura de propriedade das empresas brasileiras, a concentração de votos e o acordo de acionistas, estão associados com o conservadorismo condicional proposto por Basu (1997). Essa associação foi fundamentada pelos efeitos entrincheiramento e enforcement. Considerando que o grau de conservadorismo de uma firma está atrelado aos incentivos advindos de mecanismos que reduzem o risco informacional aos stakeholders, este estudo foi desenvolvido sobre a seguinte questão de pesquisa: Qual a influência da concentração de votos e do acordo de acionistas sobre o grau de conservadorismo nas empresas listadas na Bovespa? Cabe ressaltar que o objetivo principal deste trabalho é tratar de fatores ainda não abordados na literatura (nacional e internacional) produzida por essa linha de pesquisa, fornecendo evidências acerca da influência da estrutura de propriedade sobre o conservadorismo no mercado brasileiro, que possui conflito de agência entre acionistas majoritários (controlador) e minoritários. A amostra do trabalho perfaz 617 observações composta por empresas não financeiras negociadas na Bovespa durante o período de 2000: a 2008. Alternativamente, foi selecionada outra amostra desconsiderando as observações do ano de 2008, de forma a expurgar os efeitos da crise financeira registrada nesse ano. As evidências indicam que a concentração de votos contribui para diminuir o grau de conservadorismo, enquanto, por outro lado, o acordo de acionistas contribui para aumentar. Alternativamente, os resultados considerando o ano da crise global distorcem o funcionamento do modelo de Basu (1997). Espera-se que este estudo contribua para investidores, reguladores, pesquisadores e analistas no entendimento da função da informação contábil no processo de governança das firmas.

Palavras-chave: Concentração de vơtos. Acordo de acionistas. Efeito entrincheiramento. Efeito enforcement. Conservadorismo.

\section{ABSTRACT}

This study investigates how two features of the ownership structure of Brazilian companies, the voting rights concentration and the shareholders agreement, are associated with the conditional conservatism proposed

*Artigo apresentado no $4^{\circ}$ Congresso ANPCONT, em Natal-RN, 2010. 
by Basu (1997). This association was founded on the effects of entrenchment and enforcement. Considering that the degree of conservatism of a firm is tied to the incentives arising from mechanisms that reduce the informational risk to stakeholders, this study was developed on the following research question: What is the influence of both the voting rights concentration and shareholders agreement on the degree of conservatism in the companies listed on Bovespa? The main goal of this work is to deal with factors not yet considered in the (national and international) literature produced in this line of research, and provides evidence about the influence of ownership structure on conservatism in the Brazilian market, which is marked by a, agency conflict between controlling shareholders (controller) and minority shareholders. The sample of the paper comprises 617 observations of non-financial companies traded on Bovespa during the period from 2000 to 2008. Alternatively, another sample was selected, disregarding the observations for 2008, as a means to remove the effects of the financial crisis registered that year. The evidences indicate that the voting rights concentration contributes to decrease the degree of conservatism, while, on the other hand, the stockholders agreement contributes to an increase. Alternatively, the results considered in the global crisis year distort the Basu model (1997). The researchers hope this study contributes for investors, regulators, researchers and analysts to understand the function of accounting information in companies' governance process.

Keywords: Voting rights concentration. Shareholders agreement. Entrenchment effect. Enforcement effects. Conservatism.

\section{CONTEXTUALIZAÇÃO E MOTIVAÇÃO AO TEMA}

Para a pesquisa em contabilidade, o conservadorismo significa o reconhecimento assimétrico das más notícias nos lucros, no qual as perdas econômicas futuras são antecipadamente reconhecidas nos lucros contábeis. Essa assimetria deve-se ao próprio mecanismo contábil que requer mais materialidade no reconhecimento da substância econômica dos ganhos do que das perdas (BASU, 1997; WATTS, 2003).

Desde o trabalho seminal publicado por Basu (1997), outros trabalhos (BALL; KOTHARI; ROBIN, 2000; LUBBERINK; HUIJGEN, 2000; PENMAN; ZHANG, 1999; POPE; WALKER, 1999; WATTS, 2003) se dedicaram a estudar o conservadorismo em diversos contextos. Uma recente corrente de trabalhos procura pesquisar a relação entre o conservadorismo e os fatores relacionados à estrutura de propriedade das empresas (BONA-SÁNCHEZ; PÉREZ-ALEMÁN; SANTANA-MARTÍN, 2009; LA FOND; ROYCHOWDHURY, 2008; LARA; OSMA; PENALVA, 2009). No Brasil, alguns trabalhos abordaram o tema conservadorismo, tanto o condicional como o incondicional (COSTA; LOPES; COSTA, 2006; SANTOS; COSTA, 2006; COELHO; LIMA, 2007), porém, ainda não o investigaram sobre perspectivas relacionadas à estrutura de propriedade.

Considerando que o conflito de agência exerce influência sobre a qualidade das informações contábeis e que dada à realidade do mercado acionário brasileiro, em que o conflito de agência ocorre principalmente entre acionistas majoritários (controladores) e minoritários, este estudo tem o objetivo de investigar a relação entre o conservadorismo e dois mecanismos presentes na estrutura de propriedade das firmas negociadas no mercado brasileiro: a concentração de votos e a presença de acordo de acionistas.

Trabalhos que estudaram a estrutura de propriedade das empresas brasileiras verificaram as seguintes características: (i) o alto grau de concentração dos votos sob o controle do acionista majoritário, (ii) a ampla utilização da emissão de ações sem direito a voto (preferenciais) e (iii) a utilização de estruturas piramidais de controle (CARVALHALDA-SILVA, 2004; OKIMURA et al., 2007; SILVEIRA; BARROS; FAMÁ, 2004; VALADARES; LEAL, 2000). Além dessas, podemse citar outras duas características relacionadas ao ambiente de governança corporativa do mercado brasileiro que afetam a estrutura 
de propriedade: (i) a adoção de práticas diferenciadas de governança corporativa e (ii) o uso de instrumentos legais, como o acordo de acionistas, que podem reduzir o conflito de agência entre os stakeholders das empresas.

Por fornecerem incentivos relacionados às escolhas contábeis e ao processo de elaboração e divulgação das demonstrações financeiras, destacam-se, entre as características, a concentração de votos e a adoção de acordo de acionistas. A primeira, a concentração de votos, representa o controle que o acionista majoritário possui por ter a maioria dos direitos a voto e, tendo consequentemente, o poder de decisão sobre os números contábeis, inclusive, entre reconhecer as perdas econômicas ou usufruir dos benefícios privados do controle. E a segunda, o acordo entre acionistas pode ser considerado como um mecanismo que disciplina os interesses dos acionistas controladores e, por isso, representa um mecanismo de enforcement sobre a divulgação das demonstrações financeiras com maior qualidade.

Como as duas características destacadas, a concentração de votos e o acordo de acionistas, podem influenciar o processo de elaboração e divulgação das demonstrações financeiras, eles podem fornecer incentivos que influenciam no reconhecimento oportuno das perdas econômicas nos resultados contábeis, uma vez que reduzem a assimetria de informações entre insiders e outsiders.

Considerando que o grau de conservadorismo de uma firma está atrelado aos incentivos advindos de mecanismos que reduzem o risco informacional aos stakeholders, este estudo foi desenvolvido sobre a seguinte ques- tão de pesquisa: Qual a influência da concentração de votos e do acordo de acionistas no grau de conservadorismo das empresas listadas na Bovespa?

Esta pesquisa contribui com a literatura das seguintes formas: (i) apresenta evidências sobre o impacto da concentração de votos no conservadorismo; (ii) levanta evidências sobre o impacto do acordo de acionistas no conservadorismo; (iii) este trabalho difere dos outros por tratar de fatores ainda não abordados pela literatura; (iv) fornece evidências sobre a influência da estrutura de propriedade no conservadorismo no mercado brasileiro, que possui conflito de agência entre acionistas majoritários (controlador) e minoritários.

A importância do tema aqui abordado é sugerida por Haw et al. (2004, p. 429), "although the effect of controlling ownership structures on income conservatism certainly presents a fruitful avenue for future research [...]". Indiretamente, as evidências desta pesquisa podem ampliar o conhecimento sobre o impacto do ambiente de governança corporativa, existente no mercado brasileiro, na prática contábil: o conservadorismo.

O trabalho está organizado da seguinte forma: na seção 2, são apresentadas as mais recentes evidências relacionadas ao tema estudado; na seção 3, serão desenvolvidas as hipóteses relativas à concentração de votos e ao acordo de acionistas; na seção 4; será apresentada a metodologia utilizada; na seção 5 , os resultados encontrados serão discutidos e, por fim, na seção 6, apresentam-se as considerações finais.

\section{CONSERVADORISMO - EVIDÊNCIAS RECENTES}

Em seu trabalho seminal elaborado sobre o conservadorismo, Basu (1997) elaborou um modelo que ganhou evidência pela sua aplicabilidade e capacidade de capturar os efeitos do conservadorismo condicional, que procura identificar como todas as perdas reconhecidas no resultado contábil seriam capturadas pelo retorno das ações (WATTS, 2003).
Rapidamente, o modelo vem sendo adaptado para capturar outros fenômenos da estrutura de governança das firmas, da função da contabilidade no processo de governança das firmas e os efeitos das instituições. Recentemente, novos estudos presentes na literatura internacional procuraram estudar a efeito de fatores relacionados à governança 
corporativa e à estrutura de propriedade das empresas sobre o conservadorismo. Em relação à governança corporativa, o estudo de Lopes e Walker (2008) apresenta evidências de que o grau de conservadorismo aumenta à medida que as firmas adotam mecanismos mais rígidos de governança corporativa.

LaFond e Roychowdhury (2008) examinaram o efeito da participação dos administradores sobre o conservadorismo. Considerando que o problema de agência entre acionistas e administradores surge da separação entre controle e propriedade, esses autores apresentaram a hipótese de que a redução da participação dos administradores na estrutura de propriedade da empresa proporciona o aumento do conflito de agência, aumentando a demanda pelo reconhecimento assimétrico das perdas. Os resultados encontrados evidenciam uma relação negativa entre conservadorismo e participação dos administradores.

Bona-Sánchez et al. (2009) analisaram, no mercado espanhol, o reconhecimento assimétrico das perdas econômicas pelos lucros contábeis sob a influência de duas variáveis da estrutura de controle: (i) a concentração acionária e (ii) a divergência entre direitos de voto e de fluxos de caixa. Os resultados encontrados indicam uma relação negativa das duas variáveis pesquisadas com o reconhecimento assimétrico das perdas econômicas. Pelos resultados encontrados, quanto maior a participação acionária do acionista controlador menor o conservadorismo e quanto maior a divergência entre os direitos menor o conservadorismo.

Já Lara et al. (2009) pesquisaram a relação entre governança corporativa e o conservadorismo. A partir de um índice formado por mecanismos internos e externos de governança corporativa, os autores procuraram verificar se o nível de governança impactava no conservadorismo. Conforme hipótese lançada pelos autores, os resultados encontrados confirmaram que as empresas que apresentaram maior nível de governança corporativa, a partir do índice utilizado, também apresentaram maiores níveis de conservadorismo.

$\mathrm{Na}$ literatura brasileira, Coelho (2007) desenvolveu uma revisão aprofundada da literatura e dos modelos de conservadorismo. Já Almeida, Scalzer e Costa (2008) analisaram os efeitos dos níveis de governança da Bovespa e o conservadorismo condicional apresentando evidências de que as firmas listadas em tais níveis que oferecem práticas diferenciadas de governança, são, em média, mais conservadoras que as demais.

Em relação ao tema aqui abordado, o trabalho de Gonzaga e Costa (2009) analisou a diferença entre direitos de votos e de fluxo de caixa sob a perspectiva dos conflitos de acionistas minoritários e controladores sobre a política de dividendos, utilizando proxies para o conservadorismo baseadas nos accruals e no índice book-to-market. Os resultados encontrados pelos autores indicaram uma relação entre o conservadorismo e os conflitos sobre a política de dividendos.

\section{DESENVOLVIMENTO DAS HIPÓTESES}

\subsection{Conservadorismo e concentração de votos}

A concentração dos votos é definida como a participação de direitos de votos do(s) acionista(s) controlador(es) sobre o total de direitos de votos em uma sociedade (FA; WONG, 2002; SARLO NETO, 2009; WANG, 2006).

Dependendo do mercado acionário, a concentração de votos pode ser maior ou menor. Nos mercados acionários dos Estados Unidos e Reino Unido, a concentração dos votos é pequena, assim, nesses mercados um número grande de acionistas possui pequenas participações nos direitos de votos. Em outros mercados, como o brasileiro, ocorre a situação oposta, em que um número pequeno de acionistas possui grandes participações no total de votos (SARLO NETO et al., 2009).

O controle da empresa é exercido pelo 
acionista ou grupo de acionistas que possui a maioria dos votos para eleger e empossar os administradores. Com o controle efetivo da empresa, o acionista controlador possui, também, certo grau de influência na elaboração e divulgação das informações contábeis, nas quais estão incluídos os lucros a serem divulgados e os dividendos as serem distribuídos.

Considerando o mercado brasileiro, em que os acionistas minoritários possuem a garantia, pela legislação societária, da preferência no recebimento dos dividendos, ainda persiste a incerteza de que o acionista controlador possa se comportar de forma oportunista expropriando os seus direitos de diversas formas, que pode ser da destinação de ativos para o uso particular até a transferência de resultados para outras sociedades controladas pelo acionista controlador (FAN; WONG, 2002; SARLO NETO et al., 2009).

Se o acionista controlador, por ter o efetivo controle da empresa possui incentivo de expropriar a riqueza dos minoritários, então, esse mesmo acionista controlador que também possui o controle da confecção de suas demonstrações contábeis, terá o incentivo para não divulgar eventos ou operações que tenham potencial para sinalizar aos minoritários a expropriação realizada. Essa intenção ou a tentativa de não divulgar os eventos relacionados à expropriação dos minoritários é definido como efeito entrincheiramento.

$\mathrm{O}$ efeito entrincheiramento está diretamente relacionado ao controle da empresa e os investidores conhecem os incentivos do acionista controlador para omitir a publicação de dados que possam aumentar o monitoramento de sua gestão. Tendo conhecimento desse comportamento, os investidores tenderam a não confiar, dispensando menos atenção às informações geradas por empresas que apresentem altos níveis de concentração dos votos, provocando uma menor demanda por conservadorismo nos lucros divulgados.

Sob a perspectiva apresentada, o efeito entrincheiramento torna a contabilidade menos oportuna. A contabilidade oportuna é aquela que incorpora o retorno da ação no período (BALL; KOTHARI; ROBIN, 2000). E sendo não oportuna, a contabilidade será menos conservadora por não incorporar adequadamente as perdas econômicas. $\mathrm{O}$ efeito entrincheiramento, originado pela concentração de votos, leva à perda de credibilidade das demonstrações contábeis divulgadas, afetando a qualidade dos lucros contábeis.

Conhecendo os incentivos relacionados ao efeito entrincheiramento, que tornam a contabilidade menos oportuna, os investidores não demandam (exigem) uma contabilidade mais conservadora. Dessa maneira, a relação entre a concentração de votos e o conservadorismo pode ser entendida pelo esquema representado pela Figura 1.

Como representado pela Figura $1 \boldsymbol{0}$, a concentração de votos induz o surgimento do efeito entrincheiramento, que, por sua vez, inventiva uma Contabilidade menos oportuna, menos transparente, que levará à redução do reconhecimento das perdas econômicas pelo lucro contábil.

Conforme a questão de pesquisa estabelecida e fundamentação teórica comentadas, segue a seguinte hipótese envolvendo a associação da concentração de votos e o conservadorismo:

Ha: Quanto maior a concentração de votos do acionista controlador, menor o reconhecimento assimétrico das perdas econômicas nos lucros contábeis.

Essa hipótese considera que a concentração de votos, que proporciona o efeito entrincheiramento, impacta, negativamente, no conservadorismo. Essa hipótese é consistente

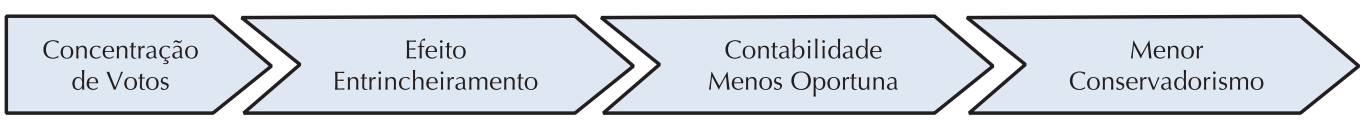


com a suposição de que o aumento da concentração de votos torna a contabilidade menos oportuna, reduzindo os incentivos para o reconhecimento das perdas econômicas pelos lucros contábeis.

\subsection{Conservadorismo e acordo de acionistas}

Estudos como os de La Porta et al. (1998) e Ball et al. (2000) indicam que a qualidade da informação contábil é maior em mercados que possuem maior enforcement sobre os direitos dos acionistas minoritários. O efeito enforcement (cumprimento) é a capacidade que o sistema jurídico possui de fazer cumprir os direitos dos acionistas minoritários em determinado mercado (SARLO NETO et al., 2009).

La Porta et al. (1998), que pesquisaram a estrutura de proteção legal dos minoritários em diversos países, constataram uma tendência de concentração da estrutura de propriedade e de controle em países que continham um menor enforcement em relação a normas de proteção aos minoritários. Para esses autores, em países onde há menor enforcement, pode existir uma facilidade maior para a expropriação dos acionistas minoritários, incentivando a concentração do controle das empresas.

O nível de enforcement varia de acordo com o sistema legal vigente em cada mercado. Em mercados em que os sistemas jurídicos são baseados no Common-Law, como o americano e o inglês, são considerados com maiores níveis de enforcement por proporcionarem um maior nível de proteção aos acionistas minoritários. Nesses países, onde o conflito de agência ocorre entre os acionistas e administradores, a propriedade é dispersa, individualmente os acionistas possuem uma participação pequena na propriedade e o seu poder de controle é pequeno.

Em relação à contabilidade, o efeito enforcement é benéfico. Um maior efeito enforcement é representado por um maior número de normas ou instrumentos dedicados a proteção de investidores. Assim, o aumento do efeito enforcement pode provocar um aumento da credibilidade/qualidade das informações contábeis. Essa afirmação é condizente com as evidências encontradas por La Porta et al. (1998) e Ball et al. (2000).

Mesmo em mercados nos quais o nível de enforcement é pequeno, os integrantes do mercado podem requerer mecanismos alternativos que, no lugar do sistema jurídico vigente no mercado, melhorem o nível de proteção dos acionistas minoritários. Devido ao não funcionamento eficiente das instituições legais, as firmas começam a adotar outros mecanismos ou padrões de comportamento para se protegerem e assegurarem o retorno aos investidores e acionistas. Por exemplo: (i) adotar mecanismos mais rígidos de governança (ALMEIDA, SCALZER; COSTA, 2008; LOPES; WALKER, 2008); (ii) sofrer pressão política por instituições extralegais, tais como meios de comunicação, competição e tax compliance (cumprimento das obrigações ficais) (HAW et al., 2004): (iii) procurar reduzir o efeito entrincheiramento, por uma mudança de comportamento alinhando os interesses entre acionistas controladores e não-controladores (FAN; WONG, 2002; WANG, 2006) e (iv) proporcionar maiores níveis de proteção aos acionistas minoritários.

O sistema jurídico presente no mercado brasileiro é baseado no Direito Civil Francês (Code Law), em particular quando consideradas as questões relacionadas ao enforcement das normas de segurança dos direitos dos minoritários.

Apesar de sua classificação (Code Law), o sistema jurídico brasileiro possui instrumentos que podem elevar o nível de enforcement sobre a elaboração e divulgação das demonstrações contábeis. Um desses instrumentos, envolvido diretamente com a estrutura de controle, particularmente, em sociedades anônimas, é o acordo de acionistas.

Com a função de disciplinar os interesses dos acionistas, o acordo de acionistas é um contrato, definido como "parassocial", por ser distinto dos outros documentos societários de uma companhia, que segue o regimento 
jurídico dos contratos civis e comerciais. A normatização do acordo de acionistas ocorreu com a Lei 6.404/76, que veio suprir uma lacuna, dispondo sobre o assunto e delimitando o alcance desse instrumento.

O ambiente brasileiro possui características diferentes e instituições que regem as relações entre insiders e outsiders. Por exemplo, o ambiente proporciona a possibilidade de as partes fazerem acordos, ou seja, contrato de acionistas, em um ambiente sem essa previsão, tal artefato de controle já poderia ter efeitos independente das partes formalizarem o acordo. No Brasil, o acordo entre acionistas pode ser um fator relevante para assegurar $\mathrm{o}$ direito dos minoritários para prevenir a expropriação por parte dos majoritários usufruindo dos benefícios privados do controle.

O impacto do acordo de acionista pode ser entendido pelo esquema representado pela Figura 20.
Como representado pela Figura 2, o acordo de acionistas proporciona um aumento do efeito enforcement, que contribui para que a Contabilidade seja mais oportuna e, portanto, mais conservadora.

Considerando o arcabouço teórico apresentado sobre a relação entre o acordo de acionistas e o conservadorismo e a questão de pesquisa, segue abaixo a seguinte hipótese:

$\mathrm{Hb}$ : A presença do acordo de acionista aumenta o reconhecimento assimétrico das perdas econômicas nos lucros contábeis.

Com base nessa hipótese, o efeito enforcement proporcionaria um impacto positivo na qualidade das informações contábeis. Logo, o acordo de acionistas aumenta a demanda por uma contabilidade mais oportuna, que corresponderá a um incentivo para o aumento no reconhecimento das perdas econômicas pelos lucros contábeis. Assim, a acordo de acionista aumentaria o conservadorismo.

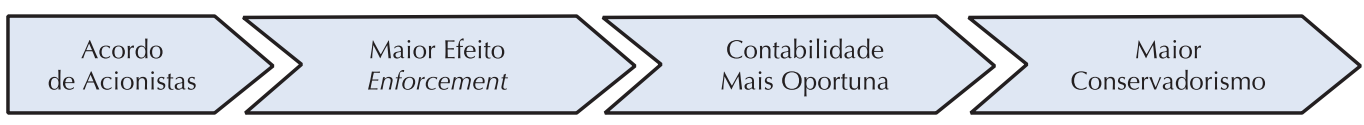

Figura 2 Relação entre acordo de acionistas e conservadorismo

\section{METODOLOGIA}

\subsection{Modelos e resultados esperados}

Para analisar o grau de conservadorismo, pesquisadores desenvolveram modelos para medir o conservadorismo condicional e o incondicional. Jenkins, Kane e Velury (2009), consideram que o modelo de conservadorismo incondicional é viesado por não capturar a realidade econômica. Os autores exemplificam da seguinte forma: uma firma que muda a vida útil de um ativo de dez para cinco anos, reduz o lucro nesse período, mas nem sempre essa decisão incorpora a vida útil do bem. Por outro lado, na perspectiva contratual o modelo de conservadorismo condicional que será apresentador a seguir, incorpora essa informação pelo mercado, fazendo com que os investidores ajustem seus modelos decisórios.
Neste estudo, o modelo que mais se ajusta à proposta apresentada no problema de pesquisa é o do conservadorismo condicional (BASU, 1997), uma vez que o mercado pode antecipar as perdas econômicas reconhecidas nos lucros contábeis no valor da empresa, dessa maneira, antecipando as perdas.

Sendo assim, foram utilizados modelos de regressão múltipla, com base no modelo inicialmente adotado por Basu (1997), que é amplamente adotado na literatura (BALL; KOTHARI; ROBIN, 2000; COELHO, 2007; LOPES; WALKER, 2008; WATTS, 1993). Os modelos foram estimados pelo método dos mínimos quadrados (MQO) e, para evitar problemas advindos da presença de heterocedasticidade, os coeficientes foram ajustados pelo método de White. Adicionalmente, 
usou-se a regressão com dados em painel (efeito fixo e efeito aleatório) para estimativa dos coeficientes dos modelos, entretanto, os resultados não mudaram significativamente.

Considerando a amplitude do problema de pesquisa, serão adotados três modelos, o primeiro consiste no modelo proposto por BASU (1997). Os outros dois modelos consistem em modificação desse modelo de forma a incorporar o impacto, individual ou conjunto, das variáveis em estudo, concentração de votos e acordo de acionistas, no conservadorismo.

- Modelo 1 (Conservadorismo-BASU): em seu fundamento está o conceito de que o lucro líquido é, em sua natureza, conservador e reconhece as más notícias antecipadamente às boas notícias que requerem uma série de elementos de verificação para o reconhecimento (LaFOND; ROYCHOWDHURY, 2008). A especificação original do modelo de conservadorismo condicional proposto por Basu (1997) é:

$$
\begin{aligned}
L L A_{i, t}= & \alpha_{0}+\alpha_{1} \cdot N E G_{i, t}+\alpha_{2} \cdot R_{i, t}+ \\
& \alpha_{3} \cdot N E G \cdot R_{i, t+} \varepsilon_{i, t}
\end{aligned}
$$

em que: $L_{L A}$ é o lucro líquido ajustado da empresa i no período t; $\mathrm{NEG}_{\mathrm{i}, \mathrm{t}}$ é uma variável dummy, quando o retorno é negativo, assume valor 1 e 0 quando o contrário; $R_{i, t}$ é o retorno da ação da empresa i no período t e $\varepsilon_{\mathrm{i}, \mathrm{t}}$ é o termo de erro.

- Modelo 2 (Estrutura de Propriedade): esse modelo foi estruturado com a finalidade de mensurar o impacto das variáveis da estrutura de propriedade (concentração de votos e acordo de acionistas) no conservadorismo. Esse modelo compreende uma modificação do modelo de conservadorismo condicional proposto por Basu (1997). A principal modificação no modelo é a inclusão da variável estrutura de propriedade (EP), que representa concentração de votos (CV) ou o acordo de acionistas (AA). Outra modificação importante é a inclusão da interação entre as variáveis da estrutura de propriedade (EP) e as variáveis que mensuram o conservadorismo (NEG e R) no modelo proposto por Basu (1997), da mesma forma que Lopes e Walker (2008) fizeram, no entanto, interagindo com índice de governança corporativa. Assim, esse modelo possui a seguinte especificação:

$$
\begin{aligned}
L L A_{i, t}= & \alpha_{0}+\alpha_{1} \cdot N E G_{i, t}+\alpha_{2} \cdot E P_{i, t}+\alpha_{3} \cdot R_{i, t+} \\
& \alpha_{4} \cdot N E G_{i, t} \cdot R_{i, t}+\alpha_{5} R_{i, t} \cdot E P_{i, t}+ \\
& \alpha_{6} \cdot N E G_{i, t} \cdot R_{i, t} \cdot E P_{i, t}+\varepsilon_{i, t}
\end{aligned}
$$

em que: $\operatorname{LLA}_{\mathrm{i}, \mathrm{t}}, \mathrm{NEG}_{\mathrm{i}, \mathrm{t}}$ e $\mathrm{R}_{\mathrm{i}, \mathrm{t}}$ possuem a mesma definição adotada pelo modelo (1). A variável $\mathrm{EP}_{\mathrm{i}, \mathrm{t}}$ representa as variáveis da estrutura de propriedade (concentração de votos e acordo de acionistas) da empresa i no período t. Dependendo da especificação, a variável EP é substituída pela variável CV (concentração de votos) ou de AA (acordo de acionista). Para o modelo (2), a interação (NEG.R.EP) é o objeto de interesse deste estudo. $O$ parâmetro $\alpha_{6}$ representa o grau da relação entre o retorno negativo da ação (NEG.R) e a variável da estrutura de propriedade (CV ou AA), ou seja, o reconhecimento assimétrico das perdas econômicas controlado pela variável estrutura da propriedade (CV ou AA). Se o valor estimado para o parâmetro $\alpha_{6}$ for positivo e estatisticamente significante, será uma indicação de que as variáveis da estrutura de propriedade (concentração de votos ou acordo de acionistas) proporcionam um aumento no reconhecimento assimétrico das perdas econômicas. Caso contrário, se o valor estimado for negativo e estatisticamente significante, indicará que as variáveis reduzem o reconhecimento assimétrico das perdas econômicas.

- Modelo 3 (Combinado): esse modelo é modificação do modelo 2, apresentado anteriormente. Ele procura verificar a influência conjunta da concentração de votos e do acordo de acionista (CV.AA) sobre o reconhecimento assimétrico das perdas econômicas pelos lucros contábeis. A partir da equação (2), esse modelo é dado por: 


$$
\begin{aligned}
L L A_{i, t}= & \alpha_{0}+\alpha_{1} \cdot N E G_{i, t}+\alpha_{2} \cdot R_{i, t} \\
& +\alpha_{3} \cdot N E G_{i, t} \cdot R_{i, t} \\
& +\alpha_{4} \cdot C V_{i, t}+\alpha_{5} \cdot N E G_{i, t} \cdot C V_{i, t} \\
& +\alpha_{6} R_{i, t} \cdot C V_{i, t}+\alpha_{7} \cdot N E G_{i, t} \cdot R_{i, t} \cdot C V_{i, t} \\
& +\alpha_{8} \cdot A A_{i, t}+\alpha_{9} \cdot N E G_{i, t} \cdot A A_{i, t} \\
& +\alpha_{10} \cdot R R_{i, t} \cdot A A_{i, t}+\alpha_{11} \cdot N E G_{i, t} \cdot R_{i, t} \cdot A A_{i, t} \\
& +\alpha_{12} \cdot C V_{i, t} \cdot A A_{i, t}+\alpha_{13} \cdot R_{i, t} \cdot C V_{i, t} \cdot A A_{i, t} \\
& +\alpha_{14} \cdot N E G_{i, t} \cdot R_{i, t} C V_{i, t} \cdot A A_{i, t}+\varepsilon_{i, t}
\end{aligned}
$$

em que: $\operatorname{LLA}_{\mathrm{i}, \mathrm{t}}, \mathrm{NEG}_{\mathrm{i}, \mathrm{t}}$ e $\mathrm{R}_{\mathrm{i}, \mathrm{t}}$ possuem a mesma definição adotada pelos modelos (1) e (2). $\mathrm{CV}_{\mathrm{i}, \mathrm{t}}$ é a variável concentração de votos da empresa i no período t e $\mathrm{AA}_{\mathrm{i}, \mathrm{t}}$ é a variável dummy para acordo de acionista, que assume valor 1 quando há acordo de acionistas e 0 quando o contrário. Para o modelo (3), a interação (NEG.R.CV.AA) é o objeto de interesse. Por possuírem valores esperados diferentes, concentração de votos (negativo) e acordo de acionista (positivo), o parâmetro $\alpha_{14}$ proporciona a possibilidade de mensurar o impacto conjunto da concentração de votos e do acordo de acionistas no reconhecimento assimétrico das perdas. Em relação às interações (NEG.R.CV) e (NEG.R.AA) que verificam a influência das variáveis da estrutura de propriedade (CV e AA) sobre o reconhecimento assimétrico das perdas econômicas, são esperados resultados similares aos obtidos no modelo 2 (Estrutura de Propriedade).

Pelas hipóteses de trabalho desenvolvidas, esperam-se para as variáveis dos modelos adotados no Quadro 10.

Pelos resultados listados no Quadro 1, espera-se, conforme a fundamentação das hipóteses, que a variável concentração de votos (CV) apresente valor negativo, indicando seu impacto negativo no conservadorismo. De forma oposta, espera-se que a variável acordo de acionista (AA) apresente valor positivo, in- dicando seu impacto positivo no conservadorismo. Quanto à interação entre concentração de votos e acordo de acionistas (CV.AA), o sinal é indeterminado. Caso o valor estimado seja positivo, será uma indicação de que o acordo de acionista pode funcionar como um mecanismo redutor do efeito entrincheiramento provocado pela concentração de votos. Caso contrário, o valor negativo aponta que o poder de enforcement do acordo de acionista não consegue mitigar a influência negativa da concentração de votos no conservadorismo.

\subsection{Seleção das variáveis e levantamento dos dados}

As informações necessárias foram coletadas no sistema de informação Economática ${ }^{\circledast}$ e no sistema de Divulgação Externa da Comissão de Valores Mobiliários (DIVEXT), disponível nos sites da Bolsa de Valores de São Paulo <www.bovespa.com.br> e da Comissão de Valores Mobiliários <www.cvm.gov.br>. Os dados contábeis foram extraídos das demonstrações financeiras consolidadas e são respectivos ao mesmo exercício do lucro líquido.

a) Lucro Líquido Ajustado (LLA): é o lucro líquido da empresa divulgado no exercício ajustado pelo valor de mercado da empresa.

$L L A_{i, t}=\frac{L L_{i, t}}{V M_{i, t-1}}$

em que: LLA $_{\mathrm{i}, \mathrm{t}}$ é o lucro líquido ajustado da empresa i no período t; $\mathrm{LL}_{\mathrm{i}, \mathrm{t}}$ é o lucro líquido da empresa i no período te $\mathrm{VM}_{\mathrm{i}, \mathrm{t}-1}$ é o valor de mercado da empresa i no período t-1. O Valor de mercado (VM) corresponde ao preço das ações no mercado à vista multiplicado pelo número total de ações:

Quadro 1 Resumo dos resultados esperados para cada variável

\begin{tabular}{l|l|l|l}
\hline Modelo & Foco & Variável & Coeficiente \\
\hline Modelo 2 & Concentração de votos & R.D.CV & $(-)$ \\
\hline Modelo 2 & Acordo de acionistas & R.D.AA & $(+)$ \\
\hline Modelo 3 & Interação & R.D.CV.AA & $(+$ ou -$)$ \\
\hline
\end{tabular}


$V M_{i, t}=P_{i, t} . N U M_{i, t}$

em que: $\mathrm{VM}_{\mathrm{i}, \mathrm{t}}$ é o valor de mercado da empresa i no período t; $\mathrm{P}_{\mathrm{i}, \mathrm{t}}$ é o preço das ações (ordinárias e preferenciais) da empresa i no período $t$ e $\mathrm{NUM}_{\mathrm{i}, \mathrm{t}}$ é o número de ações em circulação da empresa i no período t. Adotouse como preços dos ativos os preços de fechamento das ações no último pregão do ano.

b) Retorno da ação (R): calculado por uma janela de 12 meses, tendo, como data focal, o dia 31 de março.

$R_{i, t}=\frac{P_{i, t}-P_{i, t-1}}{P_{i, t-1}}$

em que: $\mathrm{R}_{i, t}=$ taxa de retorno da ação $i$ no período $[t, t-1], \mathrm{P}_{i, t}=$ preço da ação $i$ na data $t$ e $\mathrm{P}_{i, t-1}=$ preço da ação $i$ na data $t-1$.

c) Maior Acionista Controlador (MAC): é o acionista controlador que possui, com base na estrutura indireta, o maior percentual de direitos de votos em relação ao total de direitos de votos da empresa analisada.

$M A C_{i, t}=\max \left\{0, \frac{V_{i, t}^{j}}{T V_{i, t}}\right\}$

em que: $\mathrm{MAC}_{\mathrm{i}, \mathrm{t}}$ é o maior acionista controlador da empresa i no período $t ; V_{i, t}^{j}$ é a quantidade de votos do acionista $\mathrm{j}$ da empresa i no período t e $\mathrm{TV}_{\mathrm{i}, \mathrm{t}}$ é o total de votos da empresa i no período t.

d) Concentração dos Votos (CV): consiste na quantidade de votos que o maior acionista controlador (MAC) possui sobre o total de votos.

$C V_{i, t}=\frac{V^{M A C}}{T V_{i, t}}$

em que: $\mathrm{CV}_{\mathrm{i}, \mathrm{t}}$ é a concentração de votos; $\mathrm{V}_{\mathrm{i}, \mathrm{t}}^{\mathrm{MAC}}$ é a quantidade de votos do maior acionista controlador (MAC) da empresa i no período te $\mathrm{TV}_{\mathrm{i}, \mathrm{t}}$ é o total de votos da empresa i no período t.

Para o cálculo da concentração dos votos $(\mathrm{CV})$, foram utilizados os percentuais de ações ordinárias e preferenciais em po- der do maior acionista controlador (MAC), sendo esses percentuais apurados com base na estrutura indireta de propriedade, considerando, quando presente, a estrutura piramidal de controle das empresas. A participação de votos foi calculada com base nas informações contidas no Sistema Divulgação Externas $\left(\right.$ DIVEXT $\left.^{\circledast}\right)$, disponibilizado pela Comissão de Valores Imobiliários (CVM). A forma de cálculo da concentração de votos pela estrutura indireta está presente em vários trabalhos desenvolvidos na literatura nacional (OKIMURA et al., 2007; SARLO NETO et al., 2009; SILVEIRA et al., 2004; VALADARES; LEAL, 2000) e internacional (FAN; WONG, 2002; LA PORTA et al., 1998, 2000; WONG, 2006).

e) Acordo de acionistas (AA): representado por uma variável binária. A variável assume valor igual a 1 (um) quando a empresa possui acordo de acionista e 0 (zero) quando não possui. A informação da presença de acordo de acionistas (AA) nas empresas foi extraída do Relatório Informações Anuais IAN (Grupo 3 - Distribuição de Capital => 01- Eventos Relativos Distribuição de Capital => 5- Acordo de Acionistas) contido no Sistema Divulgação Externa (DIVEXT $\left.{ }^{\circledast}\right)$, disponibilizado pela Comissão de Valores Imobiliários (CVM).

Finalizando a coleta das informações, para retirar os outliers observados na variável lucro líquido ajustado (LLA) foram excluídas todas as observações que apresentassem valor para essa variável, inferior a $-1,5$ ou superior a 1,5 . Caso uma determinada ação tenha apresentado ausência de alguma das informações solicitadas, ela foi excluída da base.

\subsection{Seleção da amostra}

A amostra de trabalho foi formada por empresas não financeiras listadas na Bolsa de Valores de São Paulo (BOVESPA) durante os anos de 2000 a 2008. As instituições financeiras foram excluídas pelo fato possuírem um padrão contábil e regulação 
Tabela 1

Composição das amostras

\begin{tabular}{l|c|c}
\hline \multirow{2}{*}{} & \multicolumn{2}{|c}{ Amostras } \\
\cline { 2 - 3 } & Trabalho & Alternativa \\
\hline Período & $2000-2008$ & $2000-2007$ \\
\hline$N^{\circ}$ Obs. & 617 & 544 \\
\hline
\end{tabular}

específicos do Banco Central. Foi coletada, entre ordinárias e preferências, apenas uma classe de ação por empresa, aquela que apresentou a maior liquidez no período analisado. Como critério de corte para inclusão na amostra, adotou-se a liquidez mínima de 0,001 (em cada ano). Ao final da coleta de dados, a amostra de trabalho contou com 617 observações (ações/ano) de 68 empresas diferentes.

Conforme Tabela $1 \bullet$, da amostra de trabalho foi selecionada outra amostra, a amostra alternativa. Considerando que o ano de 2008 representou um período de ocorrência de forte crise nos mercados de capitais mundiais, optou-se por segregar uma amostra alternativa, na qual as observações relativas ao ano de 2008 foram excluídas, com a intenção de mitigar os efeitos da crise financeira registrada em 2008 sobre os resultados encontrados.

\section{RESULTADOS ENCONTRADOS}

\subsection{Estatística descritiva das variáveis e correlação entre variáveis}

Para o conjunto de dados extraídos, de acordo com os procedimentos indicados pela metodologia, seguem na Tabela $2 \oslash$ as estatísticas descritivas das variáveis utilizadas nos modelos adotados.

De forma a calcular o grau de associação entre as variáveis estudadas, foram calculados os coeficientes de correlação de Pearson. Os valores das correlações servem como uma referência preliminar das relações existentes entre as variáveis adotadas na pesquisa.

Pelos valores apresentados pela Tabela 3 $\bullet$, observa-se que o retorno (R) e a concentração de votos $(\mathrm{CV})$ possuem correlação positiva com o lucro líquido ajustado (LLA), porém somente o retorno (R) apresentou significância estatística (1\%). A correlação positiva e significativa, também, foi observada entre as variáveis retorno e concentração de votos.

Em relação ao acordo de acionistas (AA), conforme Tabela $4 \bullet$, observa-se que, do total de 617 observações da amostra de trabalho, $154(24,96 \%)$ possuem acordo de acionistas. Relacionando a contração de votos com o acordo de acionistas, nota-se que as obser- vações que possuem acordo de acionistas apresentam, em média, menor nível de concentração de votos do que as observações que não possuem acordo.

Tabela 2 Estatística descritiva

\begin{tabular}{l|c|c|c|c}
\hline & Média & Desvio & Mín. & Máx. \\
\hline LLA & 0,0615 & 0,2350 & $-1,36$ & 1,44 \\
\hline $\mathbf{R}$ & 0,3051 & 0,6671 & $-0,94$ & 3,61 \\
\hline $\mathbf{C V}$ & 0,5879 & 0,2505 & 0,06 & 1,00 \\
\hline
\end{tabular}

Tabela 3 Correlação entre as variáveis

\begin{tabular}{l|c|c|c}
\hline & LLA & $\mathbf{R}$ & CV \\
\hline LLA & 1,00 & & \\
\hline $\mathbf{R}$ & $0,1561^{*}$ & 1,00 & \\
\hline $\mathbf{C V}$ & 0,0454 & $0,0741^{* * *}$ & 1,00 \\
\hline
\end{tabular}

* valores significativos $\mathrm{p}<.01$; ** valores significativos $\mathrm{p}<. .05$; *** valores significativos $\mathrm{p}<.10$.

Tabela 4 Relação entre acordo de acionistas e concentração de votos

\begin{tabular}{c|c|c|c}
\hline Ano & $\begin{array}{c}\text { Sem } \\
\text { Acordo }\end{array}$ & $\begin{array}{c}\text { Com } \\
\text { Acordo }\end{array}$ & N \\
\hline 2000 & 52 & 13 & 65 \\
\hline
\end{tabular}


continuação

\begin{tabular}{c|c|c|c}
\hline 2001 & 48 & 20 & 68 \\
\hline 2002 & 45 & 16 & 61 \\
\hline 2003 & 49 & 17 & 66 \\
\hline 2004 & 49 & 20 & 69 \\
\hline 2005 & 46 & 19 & 65 \\
\hline 2006 & 58 & 17 & 75 \\
\hline 2007 & 59 & 16 & 75 \\
\hline 2008 & 57 & 16 & 73 \\
\hline Amostras & 463 & 154 & 617 \\
\hline $\mathbf{N}(\%)$ & 75,04 & 24,96 & $100 \%$ \\
\hline $\mathbf{C V}$ (Média) & 0,61 & 0,50 & 0,58 \\
\hline
\end{tabular}

\subsection{Resultados dos modelos}

\subsubsection{Resultados do Modelo 1 \\ (Conservadorismo-BASU)}

Esse modelo (1) foi estimado com a intenção de conhecer o nível de conservadorismo presente nas amostras selecionadas nesta pesquisa.

Pelos valores estimados, descritos na Tabela $5 \mathbf{0}$, observa-se que entre os valores estimados, apenas a constante e a variável NEG.R apresentaram valores significantes (1\%). A variável NEG.R registrou valor positivo, para a amostra de trabalho $(0,3878)$ e para a amostra alternativa $(0,5823)$. Os valores estimados para a variável NEG.R indicam que as perdas econômicas são reconhecidas pelos lucros contábeis. Os valores encontrados corroboram os resultados apurados por Costa et al. (2006) e, parcialmente, os encontrados por Santos e Costa (2006).

\subsubsection{Resultados do modelo 2 (Estrutura de Propriedade - Concentração de Votos)}

Esse modelo foi estimado com a finalidade de mensurar o impacto específico da concentração de votos (CV) no nível de conservadorismo.

Entre os valores estimados para o modelo 2, listados na Tabela $6 \bullet$, a maioria registrou insignificância estatística, como a exceção da constante e da variável NEG.R na amostra de trabalho, e da constante das variáveis NEG.R e NEG.R.CV na amostra alternativa.

Similar aos valores encontrados pelo modelo 1, os valores estimados para a variável NEG.R foram positivos e significantes $(1 \%)$, de $(0,5907)$ para a amostra de trabalho e de $(1,4019)$ para a amostra alternativa.

Quanto à variável NEG.R.CV, objeto de estudo desse modelo, apresentou valores negativos de $(-0,3385)$ para a amostra de trabalho e de $(-1,4411)$ para a amostra alternativa. Entretanto, somente o valor estimado sobre a amostra alternativa de-

Tabela 5 Resultados modelo 1 - Conservadorismo - BASU

\begin{tabular}{|c|c|c|c|c|}
\hline & \multicolumn{4}{|c|}{ Variável dependente (LLA - Lucro Líquido Ajustado) } \\
\hline & \multicolumn{2}{|c|}{ Amostra Trabalho ${ }^{\mathrm{a}}$} & \multicolumn{2}{|c|}{ Amostra Alternativa $^{b}$} \\
\hline & Coef. & Erro-Padrão & Coef. & Erro-Padrão \\
\hline Const. & $0.0982^{*}$ & $(9.4700)$ & $0,9575^{*}$ & $(0,1622)$ \\
\hline NEG & 0.0102 & $(0.0335)$ & 0,0122 & $(0,0325)$ \\
\hline $\mathrm{R}$ & -0.0049 & (0.0141) & $-0,0031$ & $(0,0183)$ \\
\hline NEG.R & $0.3878^{*}$ & $(0.1371)$ & $0,5823 *$ & $(0,0937)$ \\
\hline $\mathrm{R}^{2}$-ajustado & $7,36 \%$ & & $11,77 \%$ & \\
\hline Estatística-F & $17,31^{*}$ & & $25,16^{*}$ & \\
\hline $\mathrm{n}^{\circ}$ Obs. & 617 & & 544 & \\
\hline
\end{tabular}

Nota: Os valores em parênteses indicam o erro padrão robusto dos coeficientes. ${ }^{\text {a }}$ período (2000 a 2008). ${ }^{\mathrm{b}}$ período (2000 a 2007).* valores significativos $\mathrm{p}<.01$; ** valores significativos $\mathrm{p}<. .05 ; * * *$ valores significativos $\mathrm{p}<.10$. 
Tabela 6 Resultado modelo 2 - Estrutura de Propriedade - Concentração de Votos

\begin{tabular}{|c|c|c|c|c|}
\hline & \multicolumn{4}{|c|}{ Variável dependente (LLA - Lucro Líquido Ajustado) } \\
\hline & \multicolumn{2}{|c|}{ Amostra Trabalho ${ }^{a}$} & \multicolumn{2}{|c|}{ Amostra Alternativa ${ }^{b}$} \\
\hline & Coef. & Erro-Padrão & Coef. & Erro-Padrão \\
\hline Const. & $0.1110^{*}$ & $(0.0250)$ & $0.1117^{*}$ & $(0.0256)$ \\
\hline NEG & -0.0198 & $(0.0824)$ & 0.0923 & $(0.0956)$ \\
\hline $\mathrm{R}$ & 0.0559 & $(0.1374)$ & -0.1396 & $(0.1604)$ \\
\hline $\mathrm{CV}$ & -0.0265 & $(0.0383)$ & -0.0275 & $(0.0385)$ \\
\hline NEG.R & $0.5907^{*}$ & $(0.2165)$ & $1.4019 *$ & $(0.4259)$ \\
\hline NEG.CV & -0.0222 & $(0.0482)$ & -0.0279 & $(0.0502)$ \\
\hline R.CV & 0.0362 & $(0.0732)$ & 0.0412 & $(0.0740)$ \\
\hline NEG.R.CV & -0.3385 & $(0.5801)$ & $-1.4411 *$ & $(0.8108)$ \\
\hline $\mathrm{R}^{2}$-ajustado & $7,39 \%$ & & $13,41 \%$ & \\
\hline Estatística-F & $8,02^{*}$ & & $13,01^{*}$ & \\
\hline $\mathrm{n}^{\circ}$ Obs. & 617 & & 544 & \\
\hline
\end{tabular}

Nota: Os valores em parênteses indicam o erro padrão robusto dos coeficientes. ${ }^{\text {a }}$ período (2000 a 2008). ${ }^{\mathrm{b}}$ período (2000 a 2007).* valores significativos $\mathrm{p}<.01$; ** valores significativos $\mathrm{p}<. .05 ; * * *$ valores significativos $\mathrm{p}<.10$.

monstrou-se significante estatisticamente $(1 \%)$. Conforme esperado, a variável NEG.R.CV apresentou valores negativos. Esses resultados, principalmente, o registrado pela amostra alternativa, indicam que a variável concentração de votos fornece incentivos para que as firmas sejam menos conservadoras.

$\mathrm{O}$ resultado encontrado pela estimativa do modelo 2 (concentração de votos) sobre a amostra alternativa confirma a hipótese $(\mathrm{Ha})$ de que a concentração de votos impacta, negativamente, no conservadorismo, reduzindo o reconhecimento das perdas econômicas pelos lucros contábeis. Esses resultados indicam que existe o incentivo para que os acionistas controladores se aproveitem dos benefícios privados do controle, podendo afetar as decisões dos demais stakeholders e reduzindo a credibilidade da informação contábil divulgada.

\subsubsection{Resultados do modelo 2 \\ (Estrutura de Propriedade - Acordo de Acionistas)}

Similar ao modelo anterior, esse modelo foi estimado com a finalidade de mensurar o impacto específico do acordo de acionistas (AA) no nível de conservadorismo.

Conforme valores estimados, listados na Tabela $7 \bullet$, observa-se que somente a constante e as variáveis NEG.AA e NEG.R.AA apresentaram valores significantes estatisticamente. Ao contrario do modelo 1 e do modelo 2 (concentração de votos), o modelo 2 (Acordo de Acionistas) não confirmou os resultados relativos à variável NEG.R.

Para a variável NEG.R.AA, que representa o impacto do acordo de acionistas no reconhecimento da perdas econômicos pelo lucros contábeis, foram registrados valores positivos conforme esperado, $(0,6411)$ para a amostra de trabalho e $(0,9713)$ para a amostra alternativa, sendo ambos significativos a $(5 \%)$ e $(1 \%)$, respectivamente.

Os resultados encontrados no modelo 2 (Acordo de Acionistas), tanto na amostra de trabalho, como na amostra alternativa, confirmam a hipótese $(\mathrm{Hb})$ de que a concentração de votos impacta, positivamente, no conservadorismo, proporcionando um aumento no reconhecimento das perdas econômicas 
Tabela 7 Resultado modelo 2 - Estrutura de Propriedade - Acordo de Acionistas

\begin{tabular}{|c|c|c|c|c|}
\hline & \multicolumn{4}{|c|}{ Variável dependente (LLA - Lucro Líquido Ajustado) } \\
\hline & \multicolumn{2}{|c|}{ Amostra Trabalho ${ }^{a}$} & \multicolumn{2}{|c|}{ Amostra Alternativa ${ }^{b}$} \\
\hline & Coef. & Erro-Padrão & Coef. & Erro-Padrão \\
\hline Const. & $0,1028^{*}$ & $(0,0130)$ & 0.0998* & $(0.0136)$ \\
\hline NEG & $-0,0281$ & $(0,0354)$ & -0.0542 & $(0.0442)$ \\
\hline $\mathrm{R}$ & $-0,0124$ & $(0,0168)$ & -0.0102 & $(0.0170)$ \\
\hline AA & $-0,0189$ & $(0,0194)$ & -0.0165 & $(0.0199)$ \\
\hline NEG.AA & 0.1121 & $(0.0688)$ & $0.1592^{* *}$ & $(0.0724)$ \\
\hline R.AA & 0.0341 & $(0.0269)$ & 0.0321 & $(0.0271)$ \\
\hline NEG.R & 0.1871 & $(0.1270)$ & 0.2022 & $(0.2154)$ \\
\hline NEG.R.AA & $0.6411^{* *}$ & $(0.2994)$ & $0.9713^{*}$ & $(0.3144)$ \\
\hline $\mathrm{R}^{2}$-ajustado & $22,20 \%$ & & $21,45 \%$ & \\
\hline Estatística-F & $3,34^{*}$ & & $6,05^{*}$ & \\
\hline $\mathrm{n}^{\circ}$ Obs. & 617 & & 544 & \\
\hline
\end{tabular}

Nota: Os valores em parênteses indicam o erro padrão robusto dos coeficientes. ${ }^{a}$ período (2000 a 2008). ${ }^{\mathrm{b}}$ período

(2000 a 2007).* valores significativos $\mathrm{p}<.01$; ** valores significativos $\mathrm{p}<. .05$; *** valores significativos $\mathrm{p}<.10$.

pelos lucros contábeis.

Assim, os resultados para as firmas que possuem acordos de acionistas são distintos das demais firmas que não proporcionam tal mecanismo, indicando que essa relação contratual contribui para alinhar interesses entre acionistas minoritários e gestores, para que as más notícias (perdas econômicas futuras) sejam reconhecidas antecipadamente no resultado contábil. Essa evidência sugere que esse acordo funciona como um mecanismo de governança que contribui para que investidores e acionistas minoritários reduzam a percepção de risco em relação a essas firmas, uma vez que, contabilmente, se a perda for baixada de uma só vez no resultado, não haverá surpresas com possíveis perdas no futuro a respeito do evento reconhecido no resultado.

\subsubsection{Modelo 3 (Interativo - \\ Concentração de Votos e Acordo de Acionistas)}

Esse modelo possui a finalidade de mensurar o impacto conjunto da concentração de votos (CV) e acordo de acionistas (AA) no conservadorismo.

Conforme os dados listados na Tabela $8 \bullet$, verifica-se, novamente, como, no modelo 2, os coeficientes da concentração de votos são, apesar de insignificantes, negativos $\mathrm{NEG}^{\star} \mathrm{R}^{\star} \mathrm{CV}$ com $(-0,079)$ e $(-1,134)$, enquanto os coeficientes, também insignificantes, das firmas que possuem acordos de acionistas, são positivos $\left(\mathrm{NEG}^{\star} \mathrm{R}^{\star} \mathrm{AA}\right)$ em $(0,301)$ e $(0,232)$.

Em relação à variável NEG.R.CV.AA, objeto de estudo desse modelo, observouse um valor positivo, mas não significante em nenhuma das amostras. Por esse resultado, o acordo de acionistas (AA) não reduz o impacto negativo da concentração de votos $(\mathrm{CV})$ no conservadorismo.

Ainda sobre a interação entre concentração de votos e acordos de acionistas, deve-se destacar que os coeficientes obtidos para a variável $\mathrm{NEG}^{\star} \mathrm{R}^{\star} \mathrm{CV}^{\star} \mathrm{AA}$ foram positivos para as duas amostras, $(0,613)$ e $(1,205)$, porém, por não serem estaticamente significantes os coeficientes, os resultados encontrados não confirmam a possibilidade do acordo de os acionistas reduzirem o impacto negativo da concentração acionária no conservadorismo. 
Tabela 8 Resultado modelo 3: Interativo - Concentração de votos e acordo de acionistas

\begin{tabular}{|c|c|c|c|c|}
\hline & \multicolumn{4}{|c|}{ Variável dependente (LLA - Lucro Líquido Ajustado) } \\
\hline & \multicolumn{2}{|c|}{ Amostra Trabalho $^{a}$} & \multicolumn{2}{|c|}{ Amostra Alternativa ${ }^{b}$} \\
\hline & Coef. & Erro-Padrão & Coef. & Erro-Padrão \\
\hline Const. & $0.1341 *$ & $(0.0308)$ & $0.1432 *$ & $(0.0316)$ \\
\hline NEG & -0.1033 & $(0.0842)$ & -0.0209 & $(0.0977)$ \\
\hline $\mathrm{CV}$ & -0.0505 & $(0.0562)$ & -0.0706 & $(0.0585)$ \\
\hline AA & -0.0612 & $(0.0564)$ & $-0.0942 * * *$ & $(0.0544)$ \\
\hline NEG.CV & 0.1288 & $(0.1349)$ & -0.0486 & $(0.1462)$ \\
\hline NEG.AA & $0.1165^{* * *}$ & $(0.0684)$ & 0.1454 & $(0.0737)$ \\
\hline CV.AA & 0.0745 & (0.1109) & 0.1457 & $(0.1076)$ \\
\hline $\mathrm{R}$ & -0.0614 & $(0.0442)$ & -0.0697 & $(0.0445)$ \\
\hline NEG.R & 0.2449 & $(0.3270)$ & $0.9043^{* *}$ & $(0.4370)$ \\
\hline R.CV & 0.0775 & $(0.0848)$ & 0.0950 & $(0.0856)$ \\
\hline R.AA & 0.0950 & $(0.0638)$ & $0.1236^{* *}$ & $(0.0616)$ \\
\hline R.CV.AA & -0.1036 & $(0.1334)$ & -0.1654 & $(0.1296)$ \\
\hline NEG.R.CV & -0.0793 & $(0.5719)$ & -1.1341 & $(0.7625)$ \\
\hline NEG.R.AA & 0.3078 & $(0.6057)$ & 0.2318 & $(0.6422)$ \\
\hline NEG.R.CV.AA & 0.6132 & $(1.1926)$ & 1.2046 & $(1.2091)$ \\
\hline $\mathrm{R}^{2}$-ajustado & $22,28 \%$ & & $21,44 \%$ & \\
\hline Estatística-F & $2,22^{*}$ & & $4,01^{*}$ & \\
\hline $\mathrm{n}^{\circ}$ Obs. & 617 & & 544 & \\
\hline
\end{tabular}

Nota: Os valores em parênteses indicam o erro padrão robusto dos coeficientes. ${ }^{a}$ período (2000 a 2008). ${ }^{\mathrm{b}}$ período (2000 a 2007).* valores significativos $\mathrm{p}<.01$; ** valores significativos $\mathrm{p}<. .05$; *** valores significativos $\mathrm{p}<.10$.

\section{CONCLUSÕES}

Este estudo teve o objetivo de investigar a relação entre duas características observadas na estrutura de propriedade das empresas brasileiras: a concentração de votos e o acordo de acionistas, e o conservadorismo. Com base nas evidências empíricas obtidas, os resultados relativos às hipóteses de trabalho lançadas foram as demonstradas na Figura $3 \bullet$.

Sobre os resultados encontrados, podese levantar o seguinte conjunto de evidências sobre o impacto das variáveis concentração de votos e acordo de acionistas no conservadorismo:

i. Verificou-se que concentração de votos impacta, negativamente, no conservadorismo. Os resultados sugerem que quanto maior

\begin{tabular}{c|c|c}
\hline & Hipótese & Resultado \\
\hline \multirow{3}{*}{$\mathrm{Ha}$} & $\begin{array}{c}\text { Quanto maior a concentração de } \\
\text { votos do acionista controlador, } \\
\text { menor o reconhecimento assimé- } \\
\text { trico das perdas econômicas } \\
\text { pelos lucros contábeis. }\end{array}$ & \\
\hline $\mathrm{Hb}$ & $\begin{array}{c}\text { A presença do acordo de acio- } \\
\text { nista aumenta o reconhecimento } \\
\text { assimétrico das perdas econômi- } \\
\text { cas pelos lucros contábeis. }\end{array}$ & \\
\hline
\end{tabular}

Figura 3 Quadro resumo - Resultado encontrado para cada hipótese de trabalho

a concentração de votos menor o reconhecimento das perdas econômicas nos lucros 
contábeis. As evidências encontradas sobre a concentração de votos indicam a ocorrência do efeito entrincheiramento na empresas com ações negociadas na Bovespa.

ii. Os resultados apurados indicam que o acordo de acionistas influencia, positivamente, o conservadorismo e proporciona um aumento do reconhecimento das perdas econômicas nos lucros contábeis. Esses resultados sinalizam que o acordo de acionistas funciona como uma ferramenta que aumenta o enforcement sobre a elaboração e divulgação das informações contábeis.

iii. Outra evidência, ainda não observada na literatura, foi a interação entre concentração de votos e acordo de acionistas. Sobre a influência conjunta dessas duas características, os resultados não são conclusivos, pois os valores estimados não foram estatisticamente significantes.

Enquanto o estudo de Fan e Wong (2002) evidenciou que os números contábeis são menos informativos em países (Sudeste Asiático) com estrutura de propriedade similar a encontrada no Brasil. Os resultados aqui encontrados vão na mesma direção em rela- ção ao conservadorismo e a concentração de votos, indicando que as empresas com maior concentração de votos possuem números contábeis menos informativos.

No entanto, no mercado brasileiro, as firmas que possuem acordos de acionistas privilegiam o reconhecimento oportuno das perdas econômicas nos resultados contábeis aumentando a qualidade informacional da contabilidade. Os resultados sugerem que o uso de mecanismos legais, tais como o acordo de acionistas, pode aumentar a qualidade dos números contábeis.

Os resultados mostram a contabilidade exercendo sua função na governança das firmas e como os mecanismos que o mercado cria para assegurar os direitos de propriedade proporcionam ainda mais a melhoria da qualidade da informação contábil.

Como futuras pesquisas indica-se a investigação de instrumentos extra-legais, aqueles que não estão presentes no conjunto de normas do sistema jurídico, mas que podem exercer um aumento de enforcement na elaboração e divulgação das informações contábeis.

\section{Referências}

ALMEIDA, J. C. G.; SCALZER; R. S.; COSTA, F. M. Níveis diferenciados de governança corporativa e grau de conservadorismo: estudo empírico em companhias abertas listadas na Bovespa. Revista de Contabilidade e Organizações - RCO, v. 2, n. 2, p. 117-130, jan./abr. 2008.

BALL, R.; KOTHARI, S. P.; ROBIN, A. The effect of international institutional factors on properties of accounting earnings. Journal of Accounting and Economics, v. 29, p. 1-51, 2000.

$\mathrm{BASU}, \mathrm{S}$. The conservatism principle and the asymmetric timeliness of earnings. Journal of Accounting and Economics, n. 24, p. 3-37, 1997.

BONA-SÁNCHEZ, C.; PÉREZ-ALEMÁN, J.;

SANTANA-MARTÍN, D. J. Ultimate Ownership and Earnings. Conservatism. European Accounting Review, p. 1468-4497, 2009.

CARVALHAL-DA-SILVA, A. L. Governança corporativa, valor, alavancagem e política de dividendos das empresas brasileiras. Revista de Administração da USP - RAUSP, São Paulo, v. 39, n. 4, p. 348-361, out./nov./dez. 2004. COELHO, A. C.; LIMA, I. S. Qualidade informacional e conservadorismo nos resultados contábeis publicados no Brasil. Revista Contabilidade \& Finanças, São Paulo, v. 18 , n. 45 , p. $38-49$, set./dez. 2007.

COSTA, F. M.; LOPES, A. B.; COSTA, A. C. O

Conservadorismo em cinco países da América do Sul. Revista Contabilidade \& Finanças, São Paulo, n. 41, maio/ago. 2006.

FAN, J.; WONG, T. J. Corporate ownership structure and the informativeness of accounting earnings in East Asia. Journal of Accounting and Economics, v. 33, p. 401-425, 2002.

GONZAGA, R.P.; COSTA, F. M. A relação entre o conservadorismo contábil e os conflitos entre acionistas controladores e minoritários sobre as políticas de dividendos nas empresas brasileiras listadas na Bovespa. Revista Contabilidade \& Finanças, São Paulo, v. 20, n. 50, p. 95-109, maio/ago. 2009.

HAW, I. et al. Ultimate ownership, income management, and legal and extra-legal institutions. Journal of Accounting Research. v. 42, issue 2, p. 423-462, 2004. JENKINS, D. S.; KANE, G. D.; VELURY, U. Earnings conservatism and value relevance across the business cycle. Journal of Business Finance \& Accounting, v. 36, n. 9; 10, p. 1041-1058, nov./dec. 2009. 
LAFOND, R.; ROYCHOWDHURY, S. Managerial ownership and accounting conservatism. Journal of Accounting Research. v. 46, p. 101-135, 2008. LA PORTA, R. et al. Law and finance. The Journal of Political Economy, v, 106, n. 6, p. 1113-1155, 1998. LARA, J. M. G.; OSMA, B. G. O.; PENALVA, F. Accounting conservatism and corporate governance. Review Accounting Studies, v. 14, p. 161-201, 2009. LOPES, A. B.; WALKER, M. Firm-lavel inventives and the informativeness of accounting reports: an expreriment in Brazil. Working Paper, 2008. Disponível em: <http://papers.ssrn.com>. Acesso em: 09 jan. 2010.

LUBBERINK, M.; HUIJGEN, C. A wealth based explanation for earnings conservatism. Nov. 2000. Disponível em: < http:// papers.ssrn.com/>. Acesso em: 20 jan. 2010 ,

OKIMURA, R. T.; SILVEIRA, A. D. M.; ROCHA, K. C. Estrutura de propriedade e desempenho corporativo no Brasil. Revista Administração Contemporânea - RACEletrônica, Rio de Janeiro, v. 1, n. 1, p. 119-135, jan./ abr. 2007.

PENMAN, H. S.; ZHANG, X. Accounting conservatism, the quality of earnings, and stock returns. dez. 1999.

Disponível em: <http://papers.ssrn.com/ > Acesso em: 15 jan. 2010.

POPE, P. F; WALKER, M. International differences in the timeliness, conservatism and classification of earnings. Journal of Accounting Research, supplement to v. 37, p. $503-87,1999$.

SARLO NETO, A.; LOPES, A. B.; DALMÁCIO,
F. Z. A Influência da Estrutura de Propriedade sobre a Informatividade dos Lucros Contábeis Divulgados pelas Empresas Negociadas na Bovespa. In: ENANPAD ENCONTRO DA ASSOCIAÇÃO NACIONAL DE PROGRAMAS DE PÓSGRADUAÇÃO EM ADMINISTRAÇÃ̃O, 33., 2009. São Paulo (SP). Anais eletrônicos... São Paulo: ANPAD, 20009. CD-ROM.

SANTOS, L. S. R., COSTA, F. M. Conservadorismo contábil e timeliness: evidências empíricas nos demonstrativos contábeis nas empresas brasileiras com ADRs negociados na bolsa de Nova Iorque. In: ENCONTRO DA ASSOCIAÇÃO NACIONAL DE PROGRAMAS DE PÓS-GRADUAÇÃO EM ADMINISTRAÇÃO, 30., 2006, Salvador. Anais... Salvador: ANPAD, 2006. 1 CD-ROM.

SILVEIRA, H. P.; BARROS, L. A. C.; FAMÁ, R. Qualidade da governança corporativa no Brasil e os fatores que a determinam. In: ENCONTRO DA ASSOCIAÇÃO NACIONAL DE PÓS-GRADUAÇÃO EM ADMINISTRAÇÃO - 28., 2004, Curitiba. Anais eletrônicos... Rio de Janeiro: ANPAD, 2004. CD-ROM. VALADARES, S. M.; LEAL, R. P. C. Estrutura de propriedade e de controle das empresas brasileiras. Working Paper, COPPEAD, 2000.

WANG, D. Founding family ownership and earnings quality. Journal of Accounting Research, v. 44, p. 619-656, Apr. 2006.

WATTS, R. Conservatism in accounting part i: explanations and implications. Accounting Horizons, v. 17 , n. 3, p. 207-221, 2003. 